\title{
Psicologia Institucional: O Exercício da Psicologia Como Instituição
}

\author{
Marlene Guirado \\ Universidade de São Paulo
}

\begin{abstract}
RESUMO
O presente texto visa a atualizar e recolocar, agora no âmbito das mudanças de contexto conceitual e concreto do exercício da psicologia como instituição, o que já se vinha esboçando como uma proposta de Psicologia Institucional que respeitasse a especificidade de ação do psicólogo. O capítulo quatro do livro Psicologia Institucional (Guirado, 1987/2004), intitulado "Em busca de uma especificidade de atuação do psicólogo", é revisitado e revisado à luz dessas mudanças. Mais que isso, é reescrito numa tal ordem que se pode acompanhar o avanço do pensamento e da prática profissional, desde então. Partindo da diferenciação entre os modelos psicanalítico e sociológico de Psicologia Institucional, discute-se tal distinção, confluindo para uma terceira proposta, a qual permite tratar a própria psicologia como instituição, bem como permite tratar o seu exercício, no interior de outras práticas institucionais, como Análise Institucional do Discurso. Situações exemplares são destacadas para dar a conhecer essa estratégia de pensamento.
\end{abstract}

Palavras-chave: psicologia institucional; psicologia como instituição; análise institucional do discurso.

\begin{abstract}
Institutional Psychology: Psychological Practices as Institutions

This paper aims to update the proposition to an Institutional Psychology, considering the concrete and conceptual changes in our understanding of psychology as an institution. Chapter 4, titled "Looking for the specificity of psychologist work", in Institutional Psychology (Guirado, 1987/2004), is reviewed and rewritten in a way that makes it possible for the reader to follow the advancements of thinking and in practice. The starting point of this rearrangement is the discussion of the differences between psychoanalytic and sociological models in this area. The goal is to devise a new proposition: to consider psychology, on its own, as an institution, so that its exercise can be remarked as Institutional Discourse Analysis. Examples are given so as to make it understood what is this strategy of thinking psychology.

Keywords: institutional psychology; psychology as institution; institutional discourse analysis.
\end{abstract}

Desde o final da década de 1980, tenho procurado discutir a especificidade do trabalho e da pesquisa em psicologia quando esta se faz junto a outras instituições sociais. Essa discussão estendeu-se à clínica, numa inversão aparentemente contraditória, uma vez que nesse contexto, a psicologia teria tudo para "reinar absoluta", para definir o o quê e o como as coisas devem ser feitas. Afinal, pela formação, pela regulamentação da profissão bem como pela expectativa do público e dos agentes institucionais, esse é o território-rei do psicólogo. No entanto, ao partir da especificidade de atuação do psicólogo nesse contexto, como que num movimento de boomerang, acabamos por considerar o consultório como instituição e isto nos exigiu esclarecer, cada vez mais, o campo conceitual desse modo de pensar e fazer e pensar a psicologia, já então reconhecida como Psicologia Institucional.

O presente artigo visa a revisitar tais discussões, desenvolvidas nesses quase 20 anos de trabalhos contínuos e intensos. Visa a demonstrar a sustentabilidade da estratégia de pensamento que assim se organizou, no tempo e pela experiência concreta e refletida, para hoje tratar a psicologia institucional, não como uma área de atuação profissional, ao lado daquelas já conhecidas (clínica, social e do trabalho, escolar, experimental), mas como um modo de fazer concretamente a psicologia; um modo de produzi-la na interface com outras modalidades do conhecimento humano, confi- 
gurando aí seu objeto e exercendo-se ela própria como instituição.

Parece infindável essa tarefa: demonstrar a viabilidade de pensar a psicologia como instituição e daí derivar a ideia de que onde e como quer que se a exerça, estaremos de algum modo reafirmando esse seu caráter; estaremos produzindo e/ou reproduzindo uma prática, um conjunto de relações, que reconhecemos legítima e naturalmente ser... psicologia.

\section{PSICOLOGIA: INTENÇÃO E EXTENSÃO}

Há aproximadamente três décadas, começou a se tornar visível, entre nós, a preocupação de estender a psicologia para além das áreas em que habitualmente se exercia: pesquisas de laboratório, psicodiagnóstico, psicoterapias, treinamento e seleção profissional, predominantemente. Por currículo e por lei, ora mais e ora menos contraditoriamente ${ }^{1}$, o ensino e a atuação profissional vão produzindo o desenho de uma psicologia que não parece querer ficar à margem das reflexões filosóficas e sociológicas, feitas nas salas de aula, ou à margem de ações políticas das agremiações estudantis e dos movimentos sociais e comunitários em geral.

Nesse desenho da profissão, ganhou espaço o trabalho junto a instituições (aqui entendidas como organizações), sobretudo as de saúde, educação e promoção social. Em 1982, o governo do estado de São Paulo abriu vagas para psicólogos, nos serviços públicos, contribuindo para a extensão dos limites institucionais da profissão. Vários egressos das faculdades dirigiram-se para esses atendimentos que tomaram um caráter multiprofissional, dada a abertura feita, também em outras áreas. Os mestres universitários e profissionais mais experientes (entre eles, estavam psicólogos e psicanalistas que migraram da Argentina para cá) dedicavam-se à supervisão desses trabalhos. Não tardou a aparecer uma disciplina na Universidade de São Paulo, ainda optativa: Psicologia Institucional ${ }^{2}$. Com o passar do tempo, os currículos de outras faculdades foram incorporando o mesmo título.

É assim que, cada vez mais, psicologia e instituição vai se tornando um binômio conhecido e reconhecido. Tal efeito, no entanto, não resolve as questões oriundas de um trabalho que, apesar de tudo, ainda não tinha um respaldo suficiente na formação e no currículo. E, sendo as práticas concretas o carro-chefe, multiplicaram-se, quase às raias da dispersão, os modos de compreensão e intervenção. Estamos falando agora do estado das coisas no final da década de 1980 e início da de 1990. Isto de tal forma que parecia haver tantos modelos de trabalho quantos fossem os mestres e supervisores em campo. Uns se diziam sociopsicanalistas, outros psicólogos institucionais, outros ainda, analistas institucionais (e aqui, agrupava-se a maior variedade de posições, desde os adeptos de Lapassade até os de seu parceiro intelectual, Lourau; ou, desde os que assinavam uma autoria pessoal até os que se filiavam à orientação de Delleuze e Guattari; e assim por diante).

Apesar da liberalidade na nomeação daquilo que faziam, profissionais e autores sobre o tema produziam trabalhos até certo ponto diferentes sob a insígnia institucional. Em parte, deriva dessa diversidade, no limite da indiferenciação, uma vantagem para o exercício da psicologia: multiplicaram-se (e se multiplicam) iniciativas e tentativas de alargar os horizontes do pensamento e do fazer concreto, extrapolando os já distantes limites legais e provocando os psicólogos a abandonar determinadas certezas cristalizadas em suas modalidades de atuação, para abraçar desafios ainda muito tensos e informes. O que está longe de ser algo negativo.

Gradativamente, permanecem dois títulos a significar os trabalhos "junto às instituições", como se costuma dizer: Psicologia Institucional e Análise Institucional. Seriam elas a mesma coisa? A rigor, não. Vejamos.

\section{A PSICOLOGIA INSTITUCIONAL DE BLEGER: UMA INTERVENÇÃO PSICANALÍTICA}

Psicologia Institucional é um termo cunhado por $\mathrm{J}$. Bleger, psiquiatra argentino de orientação psicanalítica inglesa, que a um certo momento, buscou aliar psicanálise e marxismo para pensar a atuação do profissional em psicologia, para além das práticas terapêuticas e consultorias. Em nome dele e por meio de seus escritos, nos idos de 1970, a Psicologia Institucional cruzou fronteiras e, assim, apesar dos efeitos da repressão política que forçava os mais inquietos a "falarem de lado e olharem para o chão", novos ares pareciam poder soprar nestes brasis.

Trabalhar com psicologia institucional, portanto, é trabalhar com uma determinada abordagem psicanalítica específica. E, como Bleger o define, com essa abordagem, toma-se a instituição como um todo, como alvo da intervenção. Em seu livro Psicohigiene e Psicologia Institucional (Bleger, 1973/1984), fica claro que o psicólogo opera com os grupos, desde os de contato direto com a clientela até a direção, por 
meio de um enquadre que preserva os princípios básicos do trabalho clínico psicanalítico, bem como suas justificativas. Ainda: a compreensão que tem das relações interpessoais guarda uma formulação muito interessante: a da simbiose e ambiguidade nos vínculos e ele mesmo aproxima essa compreensão às ideias de M. Klein a respeito de posições nas relações de objeto; mais do que ao conceito de narcisismo em Freud (Bleger, 1977/1987).

Tudo isto implica que se alguém se diz trabalhando com psicologia institucional, estará, ao mesmo tempo, tomando, tanto a instituição e suas relações quanto a intervenção do psicólogo, a partir de uma perspectiva psicanalítica; ou da perspectiva de uma psicanálise. Interpretações ou assinalamentos, informados por esta compreensão das relações institucionais, definem sua inserção nos grupos, seu fazer.

Assim, apenas sumariada, a proposta de Bleger perde muito de sua riqueza e força... operativa. Para que se lhe faça justiça e para que se possam apreciar as alterações que ele mesmo faz na psicanálise que em princípio credita, recomendosobretudo a leitura dos textos O Grupo como Instituição e o Grupo nas Instituições (Bleger, 1979/1981) e Psicologia Institucional (Bleger, 1973/1984).

\section{A ANÁLISE INSTITUCIONAL DE LAPASSADE: UMA INTERVENÇÃO POLÍTICA}

Análise Institucional, por sua vez, é o nome dado a um movimento que supõe um modo específico de compreender as relações sociais, um conceito de instituição e um modo de inserção do profissional psicólogo que é de natureza imediatamente política. Desalojado do lugar de intérprete dos movimentos grupais ou interpessoais, ele não se delega a tarefa diferenciada da interpretação ou de assinalamentos; ele é, acima de tudo, um instigador da autogestão dos grupos nas organizações, um favorecedor da revelação dos níveis institucionais, desconhecidos e determinantes do que se passa nesses grupos. É um provocador de rachaduras e rupturas na burocracia das relações instituídas. Está do lado do instituinte, ainda que se questione sempre esse lugar e a própria análise como facilitadores da "liberação da palavra social dos grupos" (Lapassade, 1974/1977).

O idealizador da Análise Institucional é Georges Lapassade, psicólogo de formação, que passou a trabalhar com psicossociologia e prosseguiu com um intrigante caminho intelectual e político, o qual desembocou nesse movimento autodenominado Análise Institucional.
Por que "movimento"? Porque, num tom acalorado e ruidosamente polêmico, em princípio pelo estilo de sua escritura, praticamente, convoca adeptos a uma causa $^{4}$. Propõe uma forma de agir e pensar que deveria mobilizar todos os níveis institucionais ao mesmo tempo; e isto seria justificável por finalidades políticas (supostamente) óbvias (e) que todo leitor deveria ter! Funciona quase como uma convocação à militância. E o leitor se sente nessa condição de chamado aos brios: "Mexa-se! O que você está fazendo aí sentado? Venha engrossar as fileiras dos que rompem com a burocracia, liberam a palavra social e fazem a revolução permanente!".

Tal chamado, porém, como uma segunda voz nos escritos de seu livro mais conhecido entre nós (Lapassade, 1974/1977), traz já a ambiguidade, assumida por ele, de apresentar e criticar radicalmente a Análise Institucional que ele mesmo propõe. No "Prólogo à Segunda Edição" dessa obra, acaba por dizer, enfaticamente, sobre a ineficácia da Análise Institucional, na medida em que conta com a ação de técnicos como coordenadores e preceptores de mudança; a menos que se queira considerar, por um artifício, que a análise se dá no nível da palavra e, portanto, não tem relação automática com uma mudança na ação concreta. Por isso, não menos enfaticamente, afirma que o que se deve fazer é a Ação Direta (análise em ato), por aqueles mesmos que constituem os grupos de uma determinada instituição e/ou organização, com as lideranças nascidas de seu interior. Segundo ele, essa é a verdadeira revolução permanente que "decapita o rei", as instituições sociais dominantes. Tudo, por inspiração dos momentos históricos da revolução de 1968, na França, e ainda visando à liberação da palavra social. Ora, poucos anos mais tarde, registra-se em um "Prólogo à Terceira Edição", que a liberação a ser feita é a do corpo e que o que, então, se sustenta como ação de um profissional da psicossociologia e da psicologia é Crise Análise.

São de Lapassade distinções conceituais importantes que parecem frequentar o discurso de institucionalistas e de psicólogos afeitos a essa perspectiva de trabalho. Nem sempre citada a fonte, alguns desses termos parecem ter ganhado um sentido muito próximo ao de sua origem nesses outros discursos.

A primeira delas é a distinção instituinte/instituído. O instituinte é uma dimensão ou momento do processo de institucionalização em que os sentidos, as ações ainda estão em movimento e constituição; é o caráter mais produtivo da instituição. O instituído é a cristalização disso tudo; é o que, na verdade, se confunde com a própria instituição. 
A segunda é a distinção entre dois outros termos: organização e instituição. Organização é um nível da realidade social em que as relações são regidas por estatutos e acontecem no interior de estabelecimentos, espaços físicos determinados. A instituição é o nível da lei ou da Constituição que rege todo o tecido de uma formação social; está acima dos estatutos das organizações. Ainda, segundo Lapassade, a instituição pode ser considerada o brique-braque das determinações daquilo que atravessa os grupos de relação face a face numa organização social. A sala de aula é exemplar nesse sentido: a relação entre as pessoas é regida por normas que, em última instância, estão apoiadas no que prevê a lei maior para o ensino; nesse contexto, o professor poderá ser considerado um representante do Estado frente a seus alunos.

Menos conhecida é a concepção de burocracia que anima essa proposta. Em poucas palavras, a novidade que esse autor nos apresenta é a de que burocracia é, em princípio, uma questão de poder. Uma questão de divisão no poder, entre grupos de decisão e grupos de execução do fazer institucional, sendo que os primeiros decidem não apenas o que, mas também, o como fazer. A normatização e a comunicação vêm de cima para baixo, e não há previsão de canais legais ou legítimos para que essa relação se inverta. A regra de ouro é a obediência e a organização acaba sendo um fim em si mesma. Indivíduos e grupos acabam se munindo de um radar que possa sondar as necessidades e interesses que não os próprios. É a heteronomia de grupos e sujeitos, que corre em sentido oposto ao da autonomia.

Sobretudo com essa concepção de burocracia, Lapassade faz um mapeamento das relações institucionais, trazendo para elas a organização da separação, pelo poder de decisão, e a produção de sujeitos sem autonomia, alienados e alienadores da palavra social. As relações de poder e a ideologia têm, assim, seu contexto constituinte ${ }^{5}$.

Podemos derivar daí um alvo para ação do psicólogo. E, com isso, voltamos ao início e título desse item: trata-se, nessa perspectiva, de um trabalho imediatamente político, e apenas mediatamente psicológico.

Tudo o que aqui se apressou em dizer é apenas um convite ao leitor para que consulte esse intrigante livro (Lapassade, 1974/1977).

Como dissemos anteriormente, a nomeação Análise Institucional estendeu-se a uma variedade de compreensões e modos de atuação, sobretudo os psicanalíticos. De tal forma que, hoje, a referência comum tem sido o fato de se tratar de trabalhos institucionais e/ou junto a instituições. Em geral, quando conduzidos na forma de supervisão do trabalho de profissionais de ação direta.

\section{O EXERCÍCIO DA PSICOLOGIA COMO INSTITUIÇÃO}

Até aqui, buscamos caracterizar o contexto do exercício profissional da psicologia, em que foi se constituindo e firmando uma modalidade de intervenção que saía do âmbito dos atendimentos clínicos, das pesquisas laboratoriais, das escolas e das empresas, como ocasião de psicodiagnósticos, seleções e treinamentos; que saía, ao mesmo tempo, do perímetro legal que havia sido conquistado, estendendo-se e produzindo outros sentidos (extensões e intenções); constituindo uma modalidade de intervenção que, com isso, passa a se dizer institucional ao ser exercida junto a instituições.

O leitor poderia considerar que a frase acima é, praticamente, um pleonasmo: institucional porque junto a instituições. Na verdade, ela porta uma diferenciação bastante significativa e que tentarei a partir de agora esclarecer. Voltando ao início deste texto, é essa a tarefa que me parece infindável: a de demonstrar essa diferença.

Bem, toda diferença exige que se anuncie o outro polo, ou simplesmente, o contraponto. Tendo eu iniciado meus estudos teóricos sobre o assunto, ao vivo, com institucionalistas, em geral argentinos, fui depois, aos poucos, me dirigindo a leituras vindas d'além mares. Primeiramente, Lapassade teve efeitos em minha prática profissional, que eu passava, então, a designar como se dando "no nível organizativo/político, do interior do exercício da própria psicologia". Depois, mais diretamente, entro em contato com os escritos de Michel Foucault, por influência de um autor nacional, José Augusto Guilhon Albuquerque. Enquanto isso, os estudos da psicanálise de Freud e, com o tempo, da Análise do Discurso Francesa no que dela dava a conhecer Dominique Maingueneau, foram ganhando espaço. Como quem não se poupa de colocar no papel as ideias que lhe começam a fazer sentido, sobretudo porque elas faziam sentido no exercício concreto da psicologia, (no ensino e nas atuações profissionais que marcadamente guardavam uma perspectiva sempre institucional) escrevi dois livros. E, a partir daí, não parei mais de enfrentar as implicações de assim pensar; isto, num diálogo com as produções desses autores bem como numa interlocução com os 
alunos dos cursos que ministro, com os orientandos e suas pesquisas, com os trabalhos de colegas afeitos também ao estudo das instituições e da psicologia como profissão. A clínica psicanalítica como análise de discurso e a questão do sujeito na pesquisa em psicologia têm sido, ultimamente, ocasião de prosseguir organizando as ideias e, nisso, demonstrar que é possível configurar uma estratégia de pensamento que tome a psicologia como instituição do conhecimento e da prática profissional, onde e como quer que ela se dê, na ação direta de seus atores: o psicólogo e seu cliente, o professor e seus alunos, o escritor e seus leitores.

E se o leitor estiver, agora, um pouco reticente quanto às possibilidades dessa estratégia de pensar, não lhe tiro a razão, mas faço disso um desafio para a demonstração de sua viabilidade. Mais: inicio pelo recorte conceitual que precisou ser feito para que essa psicologia institucional, que ora apresentamos, mostre a que veio. A ponto de o título Psicologia Institucional, tomado para nomear práticas psicológicas junto às instituições/organizações conforme se viu nos modelos anteriores, mostrar-se limitado, pois enfatiza, ou melhor, pode recair numa questão de áreas de atuação. Nossa proposta visa a dizer, não de uma área de atuação, mas de um certo dispositivo metodológico, de um certo modo de produzir psicologia.

\section{O CAMPO CONCEITUAL DESSA NOVA PROPOSTA}

A base diferencial de nossa proposta é o conceito de instituição com que trabalhamos: conjunto de relações sociais que se repetem e, nessa repetição, legitima-se (Guilhon Albuquerque, 1987/2004). Essa legitimação se dá, em ato, pelos efeitos de reconhecimento de que essas relações são óbvias e que naturalmente sempre foram assim. Dá-se, ao mesmo tempo e complementarmente, pelos efeitos de desconhecimento de sua relatividade. A escola, por exemplo, é uma criação da modernidade, mas é muito pouco provável que seus agentes e sua clientela consigam imaginar a relatividade dessa forma de ensinar. Professores e alunos, na repetição silenciosa dos rituais cotidianos e na sutil disciplinarização de corpos e pensamentos, reconhecem que se pode até pensar e melhorar uma ou outra coisa, mas, para ensinar tem que ter escola! E que sempre foi assim! No detalhe: é comum ouvir de professores queixas com relação aos desmandos de coordenadores e supervisores de seus trabalhos e, enquanto isso, com exigência não menos veemente, não abrem mão de receber uma programação pronta para suas aulas. Da parte dos alunos: quanta relutância em aprender a pensar, quando isto significa desacomodar-se da posição de ouvinte e do "privilégio conquistado" de diluir-se no conjunto da sala ou de um grupo de trabalho, para responder por uma leitura ou pelo trabalho pessoal de um texto!

O mais importante nessa compreensão de instituição é que ela nos coloca, na qualidade de agentes ou de clientela, como atores em cena. É a nossa ação que faz a instituição. Que a reproduz e legitima. Inclusive, no que diz respeito aos efeitos de reconhecimento e desconhecimento. Assim, não há porque se referir à instituição como um corpo estranho, acima de nossas cabeças, com vida própria e independente de nós. Nós a fazemos. E, mesmo que à revelia de nossa consciência, reconhecemos como natural e legítimo esse fazer.

Além disso, toda instituição constitui um objeto (imaterial, impalpável): é aquilo (ou a relação básica) em nome de que ela se faz, e cujo monopólio é reivindicado numa delimitação de âmbito de ação com outras instituições (Guilhon Albuquerque, 2004). A cura, por exemplo, pode ser considerada o objeto das práticas médicas; o das práticas escolares pode ser considerado não apenas o ensino formal, como também a direção e a disciplina dos atos dos educandos, inclusive para além dos muros escolares, com a aquiescência (e a convite) da família (vide palestras de médicos, psicólogos e educadores sobre o uso de drogas, que as escolas têm oferecido aos pais, muitas vezes a pedido destes).

Por fim, cabe ainda destacar que toda instituição, basicamente, se constitui na e pela relação de clientela; isto é, na relação de agentes institucionais com os clientes dessas instituições. Estes últimos demandam um determinado serviço e os primeiros se destinam a prestá-lo. É nessa relação que se define a tensão entre posse e alienação do objeto institucional. Uma relação de poder, portanto, um jogo de forças poder/resistência, que não se dá senão no e pelo discurso.

Chegamos desse modo ao outro termo definidor do campo conceitual de nossa proposta: discurso. Com Michel Foucault, tomamos o discurso como ato, dispositivo, instituição, que define, para um determinado momento histórico e para uma região geográfica, as regras da enunciação. Nele e por ele, como dissemos acima, o jogo de forças poder/resistência se exerce e a produção de um saber ou verdade se faz concreta (Foucault, 1985, 1997).

O leitor pode estranhar que, ao falar "discurso", não usamos a palavra "palavra". O que queremos dizer 
com isso? Afinal, discurso não tem a ver com fala? De todo modo sim. De certo modo, não. Se sublinharmos nessa concepção que o discurso é dispositivo que define as regras da enunciação, entramos no campo da palavra. Mas, da palavra, entendida como o modo de enunciar e, até certo ponto, como cena enunciativa, que posiciona personagens, que distribui lugares e expectativas em torno desses lugares, como diria o linguista e analista do discurso, Dominique Maingueneau (1987/1989).

O que importa, porém, é considerar, com Foucault, que os discursos são dispositivos-ato, (por)que supõem para seu exercício uma posição, um lugar, que é um lugar na enunciação; isto é, um lugar prenhe de palavras para ouvir e para falar; com os efeitos que isto pode ter sobre a ação de um e outro em relação, num determinado contexto.

Um exemplo pode vir em nosso socorro, para que as palavras não abusem da compreensão com sua aridez. Falemos do dispositivo da clínica psicanalítica como discurso. Um observador atento pode perceber que os consultórios dos analistas têm um design que guarda semelhanças básicas. Moda? Muito provavelmente não. Do ambiente físico até o modo de se vestir, andar e se dirigir ao paciente, sobretudo nas primeiras entrevistas, há um regramento implícito da conduta do profissional que o faz sentir-se parte de uma comunidade discursiva ${ }^{6}$ : aquela dos que são analistas ou psicoterapeutas que trabalham com essa orientação. Pertencer a essa comunidade faz supor, por sua vez, que falam a mesma língua. Isso significa que, ora mais e ora menos diretamente, aprenderam das mesmas fontes teóricas, leram e creditaram os mesmos autores; ou seja, comungam as mesmas teorias e se autorizam a dizer em nome dos mesmos mestres. Também, isso implica um modo de pensar o que devem fazer como analistas, o que é análise, "quem" é o paciente, porque sente o que sente, até onde se pode ir num determinado processo.

Tudo isso se dá por um sutil enlaçamento dos efeitos das práticas de formação aos da própria repetição cotidiana dos atendimentos. Sutil, porque o reconhecimento que fazemos da teoria que aprendemos, como verdade sobre uma pessoa concreta que nos procura, é legitimação, naturalização muda do conhecimento constituído. $\mathrm{E}$, tudo isso se passa à revelia de nossas consciências.

Assim, quando recebemos um paciente em nosso consultório, nossa escuta se plasma nessa história da formação e da pertença aos grupos que falam a mesma língua. Costumo dizer que o ouvimos (ao paciente) com as palavras que temos para ouvi-lo (Guirado, 1986/2006). No momento em que diz por que nos procurou, isto já será ouvido como queixa ou demanda. E cada uma dessas palavras tem sentido muito particular, na medida em que compõem com o discurso de orientação inglesa (queixa) ou francesa (demanda). A partir daí, podemos imaginar que o problema ou sofrimento que passa a contar será tomado na rede de sentidos das teorias que o analista professa: como fantasia inconsciente, transferência, posição esquizoparanoide ou depressiva, fala ou desejo imaginário, simbólico ou, como o real. Às vezes, numa aplicação direta do saber aprendido; às vezes, numa tradução um pouco mais sofisticada. Ora, como se pode notar, entre o dizer do cliente e o ouvir do terapeuta há um desconhecimento constituinte (estrutural, por assim dizer) de sentidos.

E, tudo isso é discurso. Discurso-ato-dispositivo (Guirado, 1986/2006), que vai desde a pertença ao grupo dos que sabem sobre o inconsciente e preparam o ambiente físico em que este será dito, experienciado ou vivido na relação com o profissional, até as interpretações nossas de cada dia. Claro, sempre com a participação do paciente, o que porta o discurso da procura por atendimento e, nesse gesto, expõe-se à compreensão que dele tem o analista.

\section{A PROPOSTA}

Entre filósofos, linguistas e sociólogos, como posicionar uma proposta para pensar a psicologia e fazê-lo na qualidade de psicólogos?

Parece contra-senso falar em especificidade de atuação profissional e operar conceitualmente na interface com outras áreas do conhecimento. No entanto, como disse certa vez Maingueneau (2000), é preciso pensar com paradoxos. Ou ainda, só na interface marcam-se os limites do próprio. Vejamos.

Com o conceito de instituição com o qual trabalhamos, podemos considerar a psicologia como instituição do conhecimento e da prática profissional. Com o conceito de discurso como dispositivo-ato-instituição, podemos tomar o exercício da psicologia como discurso que produz e reproduz verdades, num jogo de forças poder-resistência. Fazemos, portanto, desses termos, que não se estranham, o quadro referencial, a estratégia de pensamento, para dizer do que se faz quando se diz fazer psicologia. Pensar a psicologia como instituição exige configurar-lhe um objeto, algo (imaterial, impalpável) em nome de que ela se exerce e sobre que reivindica monopólio de legitimidade. 
Diante da reconhecida e decantada diversidade de psicologias que a história de nossa disciplina e profissão constituiu, torna-se necessário fazer um recorte intencional, uma escolha, para dizer de qual psicologia falamos. Em nosso caso, optamos por um recorte que a aproxima da psicanálise e, daí, pudemos considerar como sendo seu objeto: as relações, mas não aquelas imediatamente observáveis, e sim, tal como percebidas, imaginadas, por aqueles que concretamente as fazem (Guirado, 1987/2004).

Esse objeto institucional dá destaque às relações. Ora, de quais relações falamos? Daquelas que fazemos vida a fora, com direito a pensar nas relações significativas, com as figuras parentais, desde o "berço do quarto" que, segundo Freud, são também o berço de toda subjetividade e vida social possível (Freud, 1921/1981b). De um lado, segundo a psicanálise, supõe-se que essas relações sejam imaginarizadas por aqueles que a vivem, criando o universo do psíquico ou do psicológico. De outro, pode-se considerar que a família é uma instituição que se faz pela ação concreta de seus atores: pais, filhos e aproximados. Nesse caso, a história de vínculos de alguém se reedita, historicamente, na singularidade de sua organização e numa variação ou movimento de mudança inevitavelmente exigida, uma vez que as re-edições se fazem sempre na medida em que se ocupam lugares em outras instituições. Movimento, repetição, regularidade e singularidade: termos díspares, que de forma paradoxal, articulam-se para falarmos de um sujeito psíquico porque institucional, ou do matriciamento institucional do sujeito psíquico, ou ainda, da metáfora do sujeito-dobradiça (Guirado, 1987/2004, 1986/2006; Guirado \& Lerner, 2007).

O caráter denso e obscuro do parágrafo anterior se tentará explicar a partir de agora. Mas, que se registre: ele traz a chave para o entendimento do modo de pensar que ora se propõe. Os exemplos mais uma vez se prestam ao esclarecimento. Imaginemos uma situação de sala de aula em que um aluno discorda do modo como o professor conduz seu curso, e o faz em voz alta, enquanto seus colegas em atento silêncio indicam, senão na totalidade pelo menos em parte significativa deles, concordar com sua fala. $\mathrm{O}$ aluno que discorda, muito provavelmente, re-edita, naquela situação, o lugar que se viu e se vê ocupando nas relações que estabelece desde sempre em sua vida e, como tal, na mais absoluta singularidade de ser, que construiu historicamente. No entanto, o fez num movimento que se regra pelas particularidades do lugar de aluno, falando a um professor. A cena assim constituída repõe as tensões de uma relação de poder, repõe o jogo de expectativas e dirige a um incerto ponto de desfecho a depender, sempre dos mesmos fatores: movimento, repetição, regularidades e singularidade. Tudo, historicamente construído, tendendo ao reconhecimento de legitimidade de uma certa forma de se fazer o ensino e a aprendizagem.

A insistência na singularidade historicamente constituída é o tributo conceitual à psicanálise. A regularidade e a repetição, a ideia de lugares gestores de expectativas em atos que recolocam o jogo de forças e os procedimentos institucionais, justificam o operadores conceituais fronteiriços a ela a que nos referimos anteriormente. E, como se procurou demonstrar, não se trata de justaposição de explicações sobre um fato inconteste, observável e portador de uma verdade natural e óbvia que se queira, no mínimo demonstrar. Trata-se, sim, da produção de um modo de explicar que permita, ele também, um trânsito pontual de uma sociologia, uma linguística e uma filosofia, para que com elas se opere, se produza, um modo de fazer psicologia. No mínimo, respiramos os ares das diferenças, para que não fechemos o circuito de uma instituição sobre si própria, para que não levemos à exaustão o exercício da mera repetição.

Com essa postura e nessa perspectiva, um conceito psicanalítico ganha destaque, como o próprio leitor já pode ter percebido à medida que falamos de reedições e repetições: o de transferência. Se, no entanto, prosseguimos pensando nas bordas de um conhecimento, devemos investir novos esforços para a sua reinvenção.

A transferência, termo criado por Freud para nomear "uma classe de fenômenos psíquicos" que responde pela atualização de padrões inconscientes de relações amorosas vividas no passado, e com outras pessoas, agora no presente (Freud, 1912/1981a). Essa ideia foi, no decorrer de toda sua obra, dita de diferentes maneiras, sem jamais comprometer seu sentido principal: re-edições ou fac-similes dos vínculos com as figuras significativas do início da vida, quando uma situação atual se mostrar conveniente. Tal repetição é a condição de análise nas neuroses, uma vez que os conflitos afetivos podem ser revividos com o médico, tornando-se ocasião para o conhecimento dos motivos inconscientes da conduta e, em função disso, orientando a interpretação.

Saindo do contexto em que originalmente esse termo fez sentido para ser pensado em outro, tanto da prática clínica quanto da produção teórica, para que não se faça uma extensão abusiva do conceito, é 
necessário que se proceda a ajustes que o potencialize nesse novo contexto e sua rede discursiva.

Em certa ocasião escrevi sobre a exigência desses ajustes, sob pena de se incorrer no risco de a teoria funcionar como ponto-cego na escuta do analista (Guirado, 1986/2006).Em outra ocasião, ainda, sugeri a necessidade de uma reinvenção do conceito, mesmo na clínica da psicanálise, para que se ampliasse tal escuta. Isto, para inserir entre seus determinantes a ideia de que o discurso do analista faz parte do discurso em análise e de que esse discurso pode transferir, para o contexto concreto de uma sessão, as teorias creditadas como verdade sobre o paciente, que assim se antepõem à sua fala (Guirado, 2000).

Com mais razão esse trabalho se mostra importante, quando saímos do setting consultorial para operar com os termos e procedimentos da psicanálise em outro contexto que não seja o seu de origem. O que implica essa reinvenção? Em primeiro lugar, preservar o sentido de re-edição de lugares em relações que de alguma forma marcam para a pessoa o reconhecimento de si e de sua posição; mesmo que disso não se dê conta. Depois, considerar que a re-edição só se faz em relações, por sua vez instituídas, em meio a procedimentos e jogos de força e de produção de verdades, que também deixam sua marca.

A título de exemplo: o atendimento psicológico a internos da FEBEM (hoje, Fundação Casa) tem uma especificidade, mesmo considerando as diferenças que existem entre ele se dar no interior das Unidades da própria FEBEM, ou no âmbito físico dos Serviços que a Universidade presta à Comunidade. A clientela que atendemos desenvolve expectativas muito particulares em relação ao terapeuta e seu trabalho, desde a feitura de relatórios de liberação ao juiz, até mais uma ocasião de liberdade, de saída. Por sua vez, o terapeuta (em geral estagiário desses serviços) também desenvolve outras tantas expectativas (e medos, por que não?) em relação a este jovem que chega algemado ou se encontra em condições de privação de liberdade numa Unidade com uma centena de outros jovens como ele, num pátio. Talvez, prisões ou amarras de cá e de lá marquem essa dupla, colocando um no lugar de quem atende e o outro do que será ou é atendido. Demandas à parte (como se isso fosse possível), não há como operar com a ideia de transferência estrito senso, quando o que se coloca no lugar de psicólogo-terapeuta tem pequeno grau de liberdade em relação aos seus próprios estranhamentos, e quando seu parceiro em cena faz um percurso tão diferente daquele do cliente que procura um psicólogo em seu consultório...

Então não dá para trabalhar com essa clientela aos moldes da psicanálise? Claro que dá! Mas a psicanálise deverá fazer uma torção sobre seus pressupostos teóricos e seus procedimentos habituais, e isto, em princípio, na cabeça e na postura de seu agente (o terapeuta), ou o que se produzirá sob esse título correrá o risco de ser uma mimesis inócua e equivocada do que se propõe fazer (análise).

Sob qualquer justificativa, segundo a estratégia de pensamento que estamos propondo, será razoável o terapeuta entrar em cena levando o contexto imaginário, por teoria ou por convicção de experiências cotidianas exaustivamente repetidas, de um lugar de analista acima da situação concreta. Isto o levará, muito provavelmente, a construir, também no plano imaginário, uma série de explicações que impliquem apenas o seu cliente em todos os reveses desse atendimento (por exemplo, ponderar e até interpretar como intimidação, feita pelo paciente ao analista, às raias da anulação do caráter analítico do processo e do próprio analista; ou então, como resistência do que supostamente se põe cliente). Impossível não considerar o quanto que o que pode ouvir do cliente está constituído pelos medos e amarras da diferença e do desafio não suficientemente esclarecidos que esta situação apresenta.

Finalmente, e no mínimo por uma questão de coerência argumentativa, retomamos agora a questão do sujeito que as práticas psicológicas produzem, que deixamos em suspenso, há alguns parágrafos. Nossa propositura, seguindo rigorosamente os argumentos, é a de que somente quando se consideram os "enlaçamentos texto/contexto" (nas palavras de Maingueneau), ou os efeitos de reconhecimento e desconhecimentos da repetição nas relações institucionais, os lugares e a sobreposição de lugares quando duas práticas instituídas se articulam, o peso dos procedimentos na naturalização e legitimação de um discurso como ato e como instituição, é que se pode trabalhar, na sua singularidade, aquilo que nos fala e o como se apresenta, se mostra e se fala o cliente.

Daí, a importância conceitual de uma metáfora como a do sujeito-dobradiça. Com o movimento que as metáforas nos permitem, podemos dizer que o sujeito das práticas psicológicas é esse singularmente constituído nas relações que faz, nos diferentes contextos que, por sua vez fazem sua história desde o berço das (e nas) relações com as figuras que se lhe 
apresentam como significativas, até estas que, nas diferentes situações exemplares aqui retratadas, procuramos configurar.

Se considerarmos o objeto institucional da psicologia como sendo as relações tal como reconhecidas, imaginadas pelos que as fazem, onde quer que trabalhemos daremos foco à subjetividade que nessas relações se constitui.

\section{DIÁLOGOS COM A EXPERIÊNCIA E OUTROS DISCURSOS}

Quando um psicólogo é convidado ou contratado para trabalhar numa instituição que não o consultório, essas ideias e termos têm um modo muito particular de constituir sua experiência. E o primeiro fator a considerar é o lugar que ocupa na ordem formal daquela prática. Isto porque é a partir daí que será visto, reconhecido, pelos demais agentes e pela clientela bem como se reconhecerá e reconhecerá os outros grupos em seu fazer cotidiano. Poder-se-ia dizer que esse lugar lhe confere um campo de visão e de visibilidade no imaginário daquela instituição; e, ao mesmo tempo e ato, o âmbito discursivo possível do serviço que poderá prestar.

Nada que não se possa mover, à medida que tal trabalho se exerce. Mas, esse movimento exige a rigorosa disciplina de pensar, sempre, as direções de suas ações e as desses outros parceiros de lida diária. E quando se fala em mudança ou alteração, supõe-se que ela ocorra fundamentalmente na postura e na perspectiva do psicólogo; e não, como se costuma imaginar, que o psicólogo deva transformar a realidade, como se fosse dele, o lugar predestinado à crítica e alteração dos outros. Até porque, se ao fazer sua psicologia ele se dispõe a constantemente repensar o que e como se move nas relações instituídas, estará mobilizando um campo de forças e forçando um caminho na contramão das repetições e automatismos característicos das instituições. É assim que o desenho da profissão se diferencia. E, como faz parte das práticas institucionais, estas se alteram.

Disse uma vez que psicologia institucional e onipotência não combinam... De certa maneira, concordamos aqui com o que apresenta Lapassade: se algum profissional se atribui a função de liberar a palavra social de um outro grupo, quebra, na base, as possibilidades de esse grupo se apropriar de sua palavra e assim, a burocracia, como uma questão de divisão no poder, se instaura no próprio trabalho do analista institucional.
De certa maneira, também, com essa concepção, revemos as colocações de Bleger sobre a função social do psicólogo, como uma espécie de convocação moral à ação transformadora da realidade. A condição de mudança não está voltada para fora ou justaposta ao exercício da psicologia. Não é uma exigência moral. É uma ética intrínseca a esse exercício; é responder ao perigo representado pelas repetições inaudíveis e discretas de procedimentos, de discursos, consagrados, naturalizados, legitimados.

E já que voltamos a Bleger, uma questão delicada sempre retorna, quando da leitura de seu texto: segundo ele, o psicólogo institucional deve trabalhar na condição de assessor, para que seja garantida a autonomia técnica. Como o contrato na qualidade de assessor é raro e destinado a poucos profissionais, mais antigos e com uma experiência especificamente reconhecida, não recairíamos numa quase impossibilidade da própria psicologia institucional? Sim, porque os recém-formados, dificilmente seriam contratados na condição de assessores; entrariam como psicólogos, no organograma, ao lado de outros técnicos como educadores-orientadores, assistentes sociais fisioterapeutas e assim por diante. Desse modo, a possibilidade de trabalhar com a autonomia do assessor, junto aos seus pares e junto à direção, estaria comprometida, pois não seria reconhecido como quem pudesse ser autorizado para tanto.

A bem da verdade, um lugar assim delimitado, determina, de certa forma, a apreensão que ele poderá ter do conjunto das relações instituídas. Será na qualidade de técnico, submetido às exigências características de seu cargo, em relação aos outros grupos institucionais que fará parte do imaginário ali constituído.

Que fazer, então? Recusar todos os ensinamentos da Psicologia Institucional? Não propriamente. Se retomássemos a ideia de retirá-la da concepção de que seria uma área da psicologia, ao lado de outras como a escolar, a organizacional, a clínica, a experimental, a comunitária, estaríamos em vias da concepção de uma estratégia para pensar o que pode a psicologia produzir em seu exercício. Tomar, portanto, a Psicologia Institucional (se ainda se quisesse preservar o nome) como método, como estratégia de pensamento, ao invés de tomá-la como mais uma área de atuação com métodos próprios.

Por tal caminho, chegaríamos a considerar que o psicólogo, mesmo contratado por 40 horas semanais ou encaixado no lugar de técnico pelo organograma, poderia proceder a seu trabalho tendo como regra de ouro os "cortes que fazem pensar". Isto implica a 
atenção constante, como dissemos de início, à ação dos pressupostos teóricos de nossa disciplina do conhecimento, antecipando-se a qualquer análise de contexto. Implica também, mesmo que a partir de um lugar institucional restrito e restritivo (até porque, em qualquer instância e por definição, um lugar institucional sempre o é), ter sempre em mente o conjunto das práticas em que se está inserido (ou, nas palavras de Bleger, a instituição como um todo), bem como as tensões entre os grupos nessas práticas, na apropriação daquele que se configura seu objeto, aquilo em nome de que a instituição se faz.

Com essas atenções e disciplinas constitutivas de seu trabalho cotidiano, o psicólogo poderá se dedicar a uma ação junto à clientela (alunos de uma escola, pacientes de um Hospital-Dia, por exemplo), ou junto aos grupos que produzem e reproduzem a relação básica daquela instituição (professores e alunos, ou atendentes e enfermeiros e os pacientes). Ela (a ação do profissional em psicologia) será institucional se esta for a perspectiva do trabalho. E não, como habitualmente se pensa, para carrear o título, dever-se-á trabalhar com todos os grupos, principalmente com aqueles do grupo-gestor, detentores do poder de tomar decisões que atinjam a todos.

Como, concretamente, fazer isso? Acompanhando a distribuição de tempos e espaços/atividades na rotina diária (ou semanal); quem faz o que, como, quando. Acompanhando, ainda, as relações seus conflitos e tensões, incluindo aquelas de que faz parte o próprio psicólogo. Não para desenvolver paranoias, autocentramentos e onipotências, mas para configurar o jogo de expectativas criadas nas relações imediatas, como se responde a elas e a orientação que então se segue. Com atenções assim aparentemente prosaicas, podemos nos dar conta do desenho dos procedimentos e dispositivos discursivos em jogo. E, o mais importante: podemos nos implicar nele como pólos geradores de ação sobre a ação de outros, como pólos de resistência à mudança, ou ao poder, simplesmente.

Afinal, é esse o norte para que aponta o título do texto: o exercício da psicologia como instituição...

\section{REFERÊNCIAS}

Bleger, J. (1981). Temas da psicologia (R. M. M. Moraes \& L. L. Rivera, Trad.). São Paulo: Martins Fontes. (Original publicado em 1979)
Bleger, J. (1984). Psicohigiene e psicologia institucional (E. Diehl \& M. Flag, Trad.). Porto Alegre: Artes Médicas. (Original publicado em 1973)

Bleger, J. (1987). Simbiose e ambiguidade. (M. L. X. A. Borges, Trad.) Rio de Janeiro: Francisco Alves. (Original publicado em 1977)

Freud, S. (1981a). A dinâmica da transferência (J. Salomão, Trad.). Em J. Strachey (Org), Edição standard brasileira das obras psicológicas completas de Sigmund Freud (Vol. 12, pp. 131-143). Rio de Janeiro: Imago. (Original publicado em 1912)

Freud, S. (1981b). A psicologia das massas e análise do ego (J. Salomão. Trad.). Em J. Strachey (Org.), Edição standard brasileira das obras psicológicas completas de Sigmund Freud (Vol. 18, pp. 89-179). Rio de Janeiro: Imago. (Original publicado em 1921)

Foucault, M. (1985). História da sexualidade I: A vontade de saber (M. T. Albuquerque e J. A. Guilhon Albuquerque, Trad.). Rio de Janeiro: Graal.

Foucault, M. (1996). A ordem do discurso (L. F. A. Sampaio, Trad.). São Paulo: Loyola. (Original publicado em 1971)

Foucault, M. (1997). Arqueologia do saber (L. F. B. Neves, Trad.). Rio de Janeiro: Forense.

Guilhon Albuquerque, J. A. (2004). A análise de instituições concretas. Em M. Guirado (Org.), Psicologia institucional (pp. 83-103). São Paulo: EPU. (Original publicado em 1987)

Guirado, M. (2000). A clínica psicanalítica na sombra do discurso. São Paulo: Casa do Psicólogo.

Guirado, M. (2004). Psicologia institucional (2 ${ }^{\mathrm{a}}$ ed.). São Paulo: EPU. (Original publicado em 1987)

Guirado, M. (2006). Psicanálise e análise do discurso: Matrizes institucionais do sujeito psíquico. São Paulo: EPU. (Original publicado em 1986)

Guirado, M., \& Lerner, R. (2007). Psicologia, pesquisa e clínica: Por uma análise do discurso. São Paulo: FAPESP-Annablume.

Lapassade, G. (1977). Grupos, organizações e instituições (H. A. Mesquita, Trad.). Rio de Janeiro: Francisco Alves. (Original publicado em 1974)

Maingueneau, D. (1989). Novas tendências na análise do discurso (F. Indursky, Trad.). Campinas: Pontes. (Original publicado em 1987)

Maingueneau, D. (2000). Sobre o discurso e a análise do discurso. Em M. Guirado (Org.), A clínica psicanalítica na sombra do discurso (pp. 21-31). São Paulo: Casa do Psicólogo.

Recebido: 28/05/2007

Última revisão: $12 / 10 / 2009$

Aceite final: 20/10/2009 
Notas:

1 Por exemplo, a lei que regulamentou a profissão previa que os psicólogos se dedicassem ao psicodiagnóstico e à modificação de comportamento, onde fossem chamados a intervir: educação, orientação profissional, problemas de aprendizagem e assim por diante. As terapias não foram, em princípio, consideradas campo de atuação em psicologia. No entanto, uma espécie de desobediência civil foi, como quem nada quer, mais e mais, legitimando as psicoterapias como área de atuação em psicologia. Talvez pelo acotovelar entre médicos e psicólogos, nas Sessões Plenárias do Congresso, nossa profissão contentou-se com uma regulamentação que mais restringia do que ampliava seu âmbito e exercício. Mas, o fato é que, historicamente, apesar do peso que o psicodiagnóstico veio a ter, até em função da presença extensa das disciplinas de testes durante a formação, em menos de 10 anos de lei, outras práticas psicológicas foram se impondo e abrindo mercado de trabalho. Também, o ocaso dos tempos de ditadura militar encontrou o ensino da psicologia modificado pela ação de professores que passaram a ministrar disciplinas que buscavam refletir sobre as relações entre psicologia e sociedade. Dentre eles: Dante Moreira Leite, Sylvia Leser de Mello, Maria Helena Patto e Ecléa Bosi, só para citar alguns expoentes da USP. No início da década de 1980, pelas ideias de argentinos como Pichón-Rivière e Bleger, um certo modelo de trabalho com grupos dentro e fora das organizações, bem como uma forma de intervenção com o conjunto dos grupos, sobretudo em organizações de saúde e de educação ou em comunidades, sob o título de Psicologia Institucional, ganha corpo e adeptos sedentos de propostas concretas de atuações sociais com psicologia e psicanálise.

2 Em 1982, como docente da USP, propus a disciplina Psicologia Institucional, como optativa, no programa de graduação. Somente em 2003, com o novo currículo implantado, ela veio a constar como obrigatória. Apesar de ter sempre trabalhado como psicóloga numa perspectiva sócio-institucional e de tratar das articulações entre psicologia, sociologia e política, no momento da propositura da referida disciplina, não me dei conta do quanto organizava de forma particular, um contexto de atenções mais amplo, no que diz respeito à nossa profissão.

3 Uma referência a Chico Buarque em Apesar de Você (1971).

4 Leia-se para comprovar essas impressões, o "Prólogo à segunda edição" em Grupos, Organizações e Instituições (Lapassade, 1974/1977).

5 Com isso Lapassade se distancia de uma concepção de ideologia e de instituição que se firmou pela orientação marxiana de L. Althusser, em A Ideologia e os Aparelhos Ideológicos do Estado (1974).

6 Conceito introduzido por Maingueneau (1987/1989), de certa forma apoiado no de sociedades discursivas de Foucault (1971/1996): procedimentos de circulação de um discurso, que supõe o regramento das condutas como sinal de pertença a um determinado grupo.

\section{Sobre a autora:}

Marlene Guirado: Livre-Docente do Instituto de Psicologia da Universidade de São Paulo.

Endereço para correspondência: Rua Canário, 755 - apto 71 - Moema - 04521-003 São.Paulo/SP.

Endereço eletrônico: mguirado@terra.com.br. 